\author{
А. В. Птенцова \\ МГУ им. М. В. Ломоносова \\ (Россия, Москва) \\ anna.ptentsova@gmail.com
}

\title{
ГЛАГОЛ КАНУТЬ: СЕМАНТИЧЕСКАЯ ИСТОРИЯ И СТРУКТУРА МНОГОЗНАЧНОСТИ
}

Статья посвящена истории развития значений русского глагола кануть, восходящего к праслав. *kapnoti - семельфактиву от *kapati. Как показывает материал словарей и исторического подкорпуса «Национального корпуса русского языка», значения рассматриваемого глагола в восточнославянском ареале развивались в следующей последовательности: 1.1) A1 канула на $A 2$ 'капля А1 упала на поверхность А2'; 1.2) $A 1$ канул $A 2$ на $A 3$ 'человек А1 сделал так, что капля жидкости А2 упала на поверхность А3'; 2) $A 1$ канула в $A 2$ 'капля А1 упала в жидкость А2 и растворилась в ней'; 3) A1 канул в A2 'объект А1 быстро погрузился в жидкость А2, обычно в воду, и полностью перестал быть видным и доступным'; 4) A1 канул в A2 'объект А1, оказавшись в месте А2, неожиданно перестал быть видным и доступным'. Примечательным представляется тот факт, что, употребляясь в последнем (современном) значении, кануть оказывается преимущественно в таких контекстах, где так или иначе упоминается вода или реже - иная жидкость; тем самым семантика глагола во многом сохраняет связь с предыдущими значениями цепочки, являющимися в современном языке устаревшими или уходящими.

Ключевые слова: лексическая семантика, многозначность, история русского языка, Национальный корпус русского языка.

Глагол кануть восходит к праслав. *kapnoti - семельфактиву от *kapati, подвергшемуся фонетическому упрощению; ср.: «глагол на -nQti, производный от *kapati, ср. и сохранение продленного вокализма последнего» [ЭССЯ 9: 148]. Как видно из соответствующей статьи [ЭССЯ], круг значений этого глагола (в обоих вариантах - с упрощением и без него) по славянским языкам и диалектам примерно одинаков. С одной стороны, выделяется набор очень близких друг другу прямых, «физических» значений - 'капнуть', 'сочиться' и под. С другой стороны, существует блок близких переносных значений — 'переутомиться', 'истощиться', 


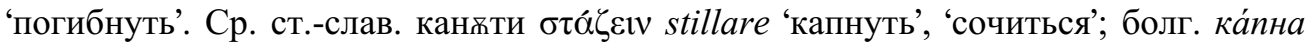
'капнуть', 'истощиться'; болг. диал. ка́nна 'капнуть', 'пролиться каплями', 'извести себя работой'; макед. капне 'капнуть', 'изнемочь'; с.-х. ка̀нути 'капнуть, пролить (каплю, слезу)', 'просочиться'; с.-х. диал. ка̀пнути, кӓпнути 'изнемочь, выбиться из сил'; чеш. книж. kanouti 'капать, течь, сочиться', kápnouti 'капать, накапать', ‘погибнуть, пропасть' и др. [Там же: 147-148].

Кроме того, этот глагол способен передавать идею появления: с.-х. диал. кӓпнути 'неожиданно явиться'; словин. kanoc 'явиться'. Наконец, чеш. книж. kápnouti может значить 'попасть, напасть' [ЭССЯ 9: 148].

Для восточнославянского ареала в [ЭССЯ 9: 148] фиксируются - наряду с 'капнуть', ‘течь', ‘пропускать воду' (арх., мурм.) - следующие значения: рус. ‘погрузиться во что-либо', блр. 'упасть в воду', укр. 'исчезать'; значение 'исчезнуть, пропасть’ фиксируется и для русских говоров Калужской и Саратовской областей. Таким образом, способность указывать на погружение объекта в жидкость и исчезновение развилась у кануть, видимо, именно в восточной группе славянских языков ${ }^{1}$.

Посмотрим теперь, как развивалась многозначность этого глагола в русском языке.

Исторические словари русского языка выделяют следующие значения каногтн.

1. 'Упасть (о капле)', ‘капнуть'; 'пролиться'; приведем несколько примеров:

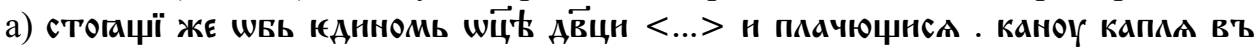
wко єга кръвнага . wсльпшєє шко н прозр - «Стояла девица, слепая на один глаз $<$... > и плакала. Капнула капля крови в ее глаз, ослепшее око и прозрело» (Пролог, XIV в. [цит. по: Словарь XI-XIV 4]; тот же пример приводится в сокращенном виде в [Словарь XI-XVII 7: 59]);

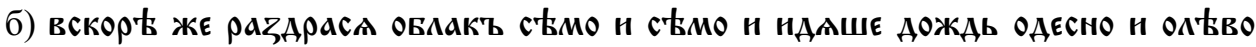

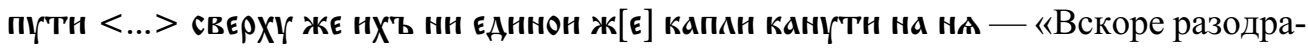
лось облако тут и там, и шел дождь слева и справа от пути, а на них сверху не капнуло ни единой капли» (Великие Четьи-Минеи митрополита Макария, XVI в. [цит. по: Словарь XI-XVII 7: 59]);

в) Аождь нє каму на Һеммю - «Дождь не пролился на земЛю» (Книга Исхода, по рукоп. Троицко-Сергиевой лавры, XIV в. [цит. по: Срезневский 1: 1191]);

г) И убиль Болеславъ брата своего Ваџлава в костель а кровь его которая канула на камень, и никоторымъ обычаемъ и доднес[ь] отмыть немочно (Козмография 1670 [цит. по: Словарь XI-XVII 7: 59]).

2. 'Пролить каплей, капнуть' (каузативное значение): н как үчнєть окнфа поспеватн и ты канн на топоръ застүАнтн - «И как начнет олифа доходить до готовности, капни [еe] на топор, чтобы остудить» (К истории обихода книгописца,

1 Значение, толкуемое при помощи глагола nponacms, существует у чеш. книж. kápnouti (см. выше), однако в данном случае пропасть входит в единое толкование с глаголом погибнуть тем самым имеется в виду именно указание на гибель, а не на исчезновение из виду, как в русском и украинском (впрочем, как видно из многозначности пропасть, смыслы 'погибнуть' и 'исчезнуть' весьма близки друг другу). 
переплетчика и иконного писца П. Симони, XVII в. [цит. по: Словарь XI-XVII 7: 59]).

Важно заметить, что перечисленные примеры ранних употреблений камогтн описывают ситуацию падения капель жидкости на твердую поверхность - причем преимущественно (кроме примера 1в) на такую, которая неспособна эту жидкость впитать. Если указание на твердую поверхность было свойственно этому глаголу во всех случаях его употребления в древнерусском и старорусском языке (в чем, к сожалению, все же невозможно быть твердо уверенным), это означает, что идея быстрого исчезновения капли, которая привела к возникновению нескольких следующих значений (см. ниже), первоначально отсутствовала в семантике каноутн. Сказанное видно особенно отчетливо на примере, иллюстрирующем второе значение: предполагается, что капля олифы не только не должна впитаться, но, наоборот, ей нужно дать застыть на холодной поверхности топора.

Обратимся к словарям современного русского языка.

«Малый академический словарь русского языка» [MAC 2: 27-28] выделяет у кануть следующие значения:

1) устар. 'упасть каплей, капнуть': Слеза повисла на реснице и канула в бокал (Пушкин);

2) 'упав куда-л., во что-л., погрузиться’: Корабль мой недвижим: стал скоро решетом / И с пушками, как ключ, он ко дну канул (Крылов); Все взрослье плотогоны в воду канули (Астафьев); Раскрылась золотая дужка, сережка канула в снега (С. Марков); к этому же значению в словаре отнесены образные употребления кануть в вечность, кануть в прошлое (отметим, что кануть в Лету [МАС] помещает во фраземы);

3) 'пропасть, исчезнуть, скрыться': Ночью Васька ушел - и уж больше не возвращзался - так и канул (Серафимович).

Первое значение, являющееся устаревшим в современном языке, все же имеет при этом небольшой семантический сдвиг по отношению к своему предшественнику каноутн: в примере, иллюстрирующем в [MAC] данное значение, капля жидкости попадает не на твердую поверхность, а в жидкость (в которой очевидным образом немедленно растворяется). Второе значение, не отмеченное в [MАС] стилистически, но, как кажется, являющееся в современном языке если не устаревшим, то, по крайней мере, уходящим, демонстрирует еще один небольшой семантический сдвиг по отношению к первому: как видно из примеров, вместо капли жидкости здесь выступает твердый предмет, который погружается или в жидкость, или в сходную с нею рыхлую субстанцию. Третье значение, выделяемое в [MАС], безусловно, является центральным для современного языка и демонстрирует значительный отрыв от предыдущих значений.

Описание глагола кануть в «Большом академическом словаре русского языка» очень близко тому, что дает [MАС], поэтому не будем обсуждать отдельно материал этого словаря; приведем для сравнения лишь данные из словаря Д. Н. Ушакова [СУш 1: 1308], описание которого, впрочем, тоже весьма сходно с описанием [MAC]: 
1) устар. ‘ ‘быстро погрузиться в воду, пойти ко дну’ (это значение иллюстрировано тем же примером из Пушкина, что и первое значение в [MAC], хотя толкование здесь соответствует второму значению $\left.[\mathrm{MAC}]^{3}\right)$; сюда же словарь относит перен., поэт. 'погрузиться, упасть куда-л. вниз, в глубину': И многое с песнями канет мне в душу на темное дно (Фет);

2) перен. 'погрузившись куда-н., пропасть, исчезнуть': кануть в вечность; Так и канул он безвозвратно в немую тьму (Тургенев).

Обсудим теперь подробнее каждое из этих значений, обратившись к данным «Национального корпуса русского языка» [НКРЯ], и посмотрим, как каждое из значений соотносится с другими.

Как можно заключить, исходя из данных исторических словарей и словарей современного русского языка, цепочка значений глагола кануть на диахронической оси выглядит следующим образом.

1. Блок наиболее старых значений:

1.1) $A 1$ канула на $A 2$ 'капля $\mathrm{A} 1$ упала на (твердую?) поверхность $\mathrm{A} 2$ '4;

1.2) $A 1$ канул $A 2$ на $A 3$ 'человек $\mathrm{A} 1$ сделал так, что капля жидкости $\mathrm{A} 2$ упала на (твердую?) поверхность АЗ'.

2. $A 1$ канула в $A 2$ 'капля $\mathrm{A} 1$ упала в жидкость $\mathrm{A} 2$ и растворилась в ней'.

3. A1 канул в A2 'объект А1 быстро погрузился в жидкость А2, обычно в воду, и полностью перестал быть видным и доступным'.

4. A1 канул в A2 'объект А1, оказавшись в месте А2, неожиданно перестал быть видным и доступным'.

Важно отметить, что, как показывают данные [НКРЯ], в значении 1.1 кануть мог употребляться еще в XIX в.: Кипящий свинец канул в ухо Бианки, и жизнь ее прервалась одним вздохом (А. А. Бестужев-Марлинский, 1830); Вот уже пять недель не кануло капли дождя на поля южного Дагестана (А. А. Бестужев-Марлинский, 1836); Он привык к слезам полковнищь и всегда смотрел на них равнодушно, но слезы Марьи Ивановны как будто канули ему на сердце (А. Ф. Вельтман, 1848). В этих контекстах, как и в примерах из исторических словарей, описаны ситуации падения капель на твердую поверхность — и тоже преимущественно на такую, которая неспособна поглотить жидкость.

То же значение встретилось и в тексте XX в.: Тощая серая слеза перебежала поле его щеки и канула в бороду (А. Веселый, 1927), - впрочем, борода здесь,

\footnotetext{
${ }^{2}$ Интересно, что заметно более ранний, чем [MAC], [СУш] подает данное значение как устаревшее, что, как отмечалось выше, точнее отражает действительность.

3 Толкование [MAC] в целом кажется более удачным, так как допускает в качестве среды, куда погружается объект, не только воду, но и любую другую жидкость и сходную с ней субстанцию, а отсутствие в этом толковании важного семантического компонента 'быстро', представленного в толковании [СУш], отчасти компенсируется компонентом 'упав', описывающим быстрое движение (однако нужно заметить, что приводимая в [MAC] иллюстрация из Крылова требует скорее толкования [СУш]: корабль не падает в воду перед тем, как затонуть, а резко погружается в нее).

4 Толкования формулируются в формате, принятом в толковом словаре [АС]: они вводятся при помощи сентенциального входа, содержащего переменные вида А1, А2 и т.д.
} 
по-видимому, осмысляется не как твердый объект, а как своего рода рыхлая поглощающая субстанция.

Значение 2 представлено в [НКРЯ] примерами из текстов XIX в. (ср. цитировавшийся выше пример из Пушкина): В это время стоявший позади лакей утер посланнику нос, и очень хорошо сделал, иначе бы канула в суп препорядочная посторонняя капля (Н. В. Гоголь, 1842).

Интересно, что и для ХХ в. это значение оказывается вполне возможным (правда, видимо, в режиме стилизации): Лодки отчалили наконеи, <... вскинулись и замерли в готовности весла, <..>капли, сверкая, скатились с них и канули в багряную воду (Л. Кабо, 1964-1997).

Условно сюда же можно отнести употребление кануть в известном стихотворении Б. Л. Пастернака:

Вы к былям звали собеседника,

К волне до вас прошедиих дней,

Чтобы последнею отцединкой

Последней капли кануть в ней.

Нужно заметить, однако, что здесь имеется поэтическая амбивалентность (капля растворяется в волне - человек погружается в воспоминания), поэтому данный контекст можно рассматривать как пример одновременной реализации обоих значений - 2 и 4.

Именно в контекстах, подобных приведенным здесь и описывающих растворение капли в жидкости, в семантике кануть формируется компонент 'исчезнуть'.

В современном языке встречаются употребления, переходные от значения 2 к значению 4 - речь в них идет о больших водных объектах, сливающихся с другими водными объектами и как бы исчезающими в них: Через пару сотен метров канет в Катунь речка Камышлинка и покатится к океану (К. Серафимов); Течет себе река и течет. И все по порядку. Родничок, верхнее течение, нижнее течение - и конец: влилась в море и канула (Ю. Домбровский). В последнем примере идея исчезновения особенно отчетливо выходит на первый план. Значение 3 встречается не только в языке XIX в., но и в настоящее время. Приведем большую подборку примеров, в основном из текстов авторов первой половины XX в. и современных: Вдруг оно [кольцо] выпало, скатилось по ноге и кануло в воду (Н. А. Бестужев); И вдруг новые Петинь башмаки<... > легко скользнули и, как во сне, канули в воду. Канули вместе со свочми новенькими гвоздиками, союзками, рантами, крючками, зелеными ушками и шнурками; Они булькнули и канули в пучину, покрытыле омерзительно-зеленой волной (В. Катаев); Он отыскивал на берегу плоский камушек и так искусно забрасывал в море, что прежде чем кануть на дно, камушек, скользя по воде, подскакивал не меньше двенадияати раз (К. Чуковский); А блюдо совершенно беззвучно исчезло под водой <...> Очнулся я, но все ясно стояло перед глазами < ... Б Брюссельские кружева, лебеди и тяжелое блюдо, без всплеска канувшее в пруд (Б. Васильев); Как долбануло - лодка на дно канула с креном и воем <..> и как не было; щеепки только вспльли и кое-какой мусор закружился 
в воронках (А. Иличевский); Шахматная доска без всплеска канула в озеро (Д. Колодан, К. Шаинян); Ухнул передовой танк в колодеи, только его и видели. Сомкнулись вязкие мармеладные воды над люком, танкисты и выбраться не успели. Захлебнулись и канули (Е. Хаецкая).

К этому же значению вслед за [MAC] нужно отнести и образные употребления кануть в небытие (в вечность, в прочлое, в безвестность).

Как и в случае с реализацией значения 2, здесь легко найти примеры промежуточного употребления - если в контекстах с кануть в значении 3 на первый план выходит та же идея исчезновения: Корабль обречен сбиться с курса, угодить в жестокий шторм, а то и вообще кануть в пучину морскую (Б. Васильев). Легко видеть, что кануть здесь означает и 'погрузиться', и 'исчезнуть'.

Перейдем к значению 4, самому употребительному в современном языке.

Наиболее интересное наблюдение, относящееся к современному кануть, касается именно этого значения и состоит в следующем: унаследованная из предшествующих значений идея жидкости, поглощающей объект, в значительной степени ощущается и здесь, хотя формально связь с жидкостью в кануть 'исчезнуть’ полностью утрачена. Рассмотрим несколько характерных употреблений такого рода.

За сорок минут нарушитель мог добраться до горелого леса и кануть в озерцах и болотах (С. Наумов). Перед нами контекст, в котором отчетливо видно, как из одного значения вырастает другое: местом действия все еще являются здесь водные объекты, но само действие меняется - субъект не погружается в воду и не тонет, а исчезает где-то посреди озер и болот, становясь недоступным для своих преследователей.

Следующим семантическим шагом становится некоторое изменение типа места - однако представление о том, что кануть как-то связано с водой, тем не менее остается: Они повернули к горбатому мостику в концее улищы, < _. > поднялись по ступеням на мост и канули - так за горизонт уходят корабли (Д. Рубина). Объективно речь здесь идет о людях, исчезнувших из поля зрения наблюдателя после того, как они оказались по другую сторону крупного объекта, но кануть (поддержанное к тому же наличием слова мост) вызывает у автора развернутую «водную» ассоциацию.

Пересекли несколько улии, дошли до Невы и как в землю канули (Ю. Домбровский). Интересно, что место, где исчезают субъекты, - не вода, а земля, но тем не менее нельзя не отметить Неву в непосредственной близости от кануть (причем земля в контексте нашего глагола мыслится как некая рыхлая субстанция, в которую можно погрузиться и которая этим своим свойством напоминает жидкость).

Рассмотрим теперь следующий примечательный контекст: A потом [Сазыкин] канул в Сибирь (Е. Замятин). На первый взгляд, в этом примере нет ничего, что напоминает о «водном» прошлом глагола кануть. Но посмотрим на то, как выглядит здесь правый контекст: А потом [Сазыкин] канул в Сибирь. Так камень бултыхнет в водяную дремь, все взбаламутит, круги: вот разбежались - только легкие морщины, как по углам глаз от улььбки - и снова гладь (Е. Замятин). 
Вот еще один совершенно аналогичный случай: Стой здесь, - велел Еж, а сам пошел направо. Но, прежде чем кануть за дверью, бросил Дюку взгляд, как бросают конец веревки, перед тем как прыгнуть в кратер вулкана. Или нырнуть в морскую глубину (В. Токарева). Заметим, что упоминание морской глубины появляется здесь вроде бы вовсе не в связи с кануть, а при описании взгляда исчезающего за дверью человека - и тем не менее понятно, что именно данный глагол спровоцировал все развернутое сравнение в целом.

«Следовое количество» воды можно усмотреть и в следующем контексте: Когда курил, он думал о прошльх друзьях, потихоньку канувших в распльвшиеся буквы записной книжки (Д. Симонова). Здесь также выражается представление о чемто наподобие жидкой мути, в которой исчезают объекты.

Подобным же образом обстоит дело и с переносными употреблениями, где кануть 'исчезнуть' находится в контексте существительных, указывающих на водные объекты или нечто подобное им: Mеры предосторожности, которые он предпринял, были не очень надежны, и если формально следовать правилам разведки, то тот, кто скрывается под этим псевдонимом, должен замереть, затаиться, кануть на долгие месяџь в водовороте крупного города (С. Наумов); Он вспомнил своих боевых товарищей, тех, которых потерял на войне и которые канули в водоворотах смутного времени (А. Проханов); И все, что она может придумать для канувиих в колодец бесконечности теней, которым так не хватало любви при жизни, - это позволить им вернуться и немного побыть продолжением того смешного, безумного и бесконечно трогательного, чем они когда-то были (В. Пелевин).

Как отмечалось выше, кануть в рассматриваемом значении часто употребляется применительно к тому, что мыслится как текучая или рыхлая, обволакивающая субстанция. Приведем подборку примеров: Он канул в туман и вернулся минут через десять (Д. Рубина); Ту-154 раз за разом таранил бесконечные облачные слои - и таки продрался к небу и свету <...>, чтобы через полчаса опять кануть в белесую баланду (А. Гаррос, А. Евдокимов); И вдруг бригадир пропал. То он ходил, бухтел, рассказывал, поддразнивал, а тут вдруг как в тучку канул (Ю. Домбровский); Мальчик еле отделил прилипший к кипе сырой листок, сунул его доктору в руки и канул в метель так же мгновенно, как из нее вынырнул (Б. Пастернак); Кондаков хмуро взглянул на часы и, не прощаясь, канул в полумраке бюро пропусков (В. Дудинцев); Летучая мышь с перепуганным писком порхнула с его плеча, обдав лицо легким дуновением, и канула во тьму (В. Рыбаков); «Фр-р», - взлетела и канула в ночи огромная птица (Г. Башкуев); Несколько минут кануло в безмолвии (Р. Шмараков); Камень на мгновение канул в тишину ${ }^{5}$ затем удар, клекот осколков (К. Серафимов).

Разумеется, кануть 'исчезнуть' используется не только в случаях, подобных описанным, т.е. не только там, где в контексте так или иначе содержится

${ }^{5}$ Безмолвие и тишина тоже мыслятся как текучая субстанция; ср. Безмолвие окутыввало <обволакивало> все вокруг; И снова тишина окутывала Обдонье (М. Шолохов). 
упоминание воды или где речь идет о чем-то, что мыслится как текучая субстанция. Для этого глагола характерны употребления, в том числе переносные, где описывается исчезновение объекта в каком-либо замкнутом пространстве или в пространстве, отделенном от наблюдателя какой-либо преградой: Длинный конверт с красивым кругльмм вензелем отеля канул в медную щель (В. Катаев); Сберегается <...> сумма в двадиать семь марок и шестьдесят пфеннигов, которая иначе канула бы в карманы тех <..> моченников, которые придумали первый класс (В. Набоков); Пленку затребовали в КГБ, где она и канула в бездонной утробе (В. Аксенов); Когда наконец все всех проводили и со всеми простились Гутман канул в дверях своего отеля (А. Пятигорский); Рукописи канули в подвалах Лубянки, вещчи пропали из разграбленной во время войны квартиры (А. Крищенко); Солнце, казалось, уже до утра канувшее за гору, вдруг снова золотило все кругом, когда дорога делала очередную петлю, взбираясь все выше и выше (В. Каминарская).

И все же большинство контекстов, содержащих кануть 'исчезнуть', так или иначе демонстрирует, что в семантике этого глагола до сих пор сохраняется память о связи соответствующего действия с водой или с другой жидкостью.

Таким образом, структура многозначности кануть представляет собой цепочку значений, из которых следующее связано с предыдущим так, что при каждом семантическом переходе заменяется ровно один компонент и соседние значения плавно переходят (уместно сказать - перетекают) одно в другое: капля падает на твердую поверхность (и обычно не впитывается ею) $\rightarrow$ капля падает в жидкость и растворяется в ней $\rightarrow$ твердый объект падает в жидкость и исчезает в ней $\rightarrow$ объект исчезает в каком-либо месте. При этом в последнем случае в значительной степени сохраняется унаследованный из диахронии семантический компонент 'жидкость'.

Сказанное еще раз иллюстрирует тот факт, что в современных значениях слов часто «просвечивают» исторически предшествующие им значения (применительно к нашему случаю хочется сказать, что предшествующие значения просачиваются в современные).

В заключение обсудим коротко другой вопрос, связанный с кануть 'исчезнуть'.

В работе [Апресян 2017] были описаны так называемые двойные семантические роли в значениях некоторых глаголов. Речь идет о случаях типа повесить на веревку - повесить на веревке, где одна и та же валентность глагола способна заполняться двумя семантическими актантами - конечной точки (выраженной формой винительного падежа - далее ВИН) и места (выраженного формой предложного падежа - далее ПР). Среди прочих типов глаголов, для которых характерен этот эффект, в работе рассматривались и так называемые глаголы с семантикой перемещения из более открытого пространства в более закрытое и последующего размещения в нем, в частности спрятаться, зарыться и закоnаться. Эти глаголы, в целом допускающие обе семантические роли, в ряде случаев, однако, демонстрируют явные предпочтения ВИН или ПР падежей. В. Апресян отмечает, что, когда речь идет о больших пространствах, глагол спрятаться 
естественней употребить с ПР: спрятаться в горах (но не *спрятаться в горы); в значении 'находиться в закрытом месте незаметно для наблюдателя' возможен только ПР: Гриб спрятался под елкой, но не *Гриб спрятался под елку; ПР пред-

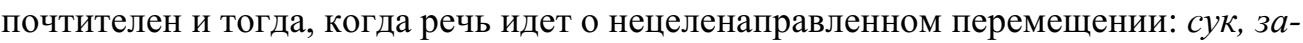
копавиийся в песке (но не * в песок).

Кануть относится к той же семантической группе и допускает то же колебание ВИН - ПР. Нужно повторить, что двойная роль возможна лишь для кануть в 4 значении; в прочих же случаях возможна лишь форма ВИН. Причина этого понятна: ВИН является единственно допустимым падежом до тех пор, пока кануть связан с идеей падения, т. е. перемещения, и указывает на конечную точку этого перемещения. Но как только в кануть становится преобладающей идея исчезновения, становится возможна и форма ПР, указывающая на место, где исчезает объект. Заметим попутно, что глагол исчезнуть допускает только идею места: исчезнуть в чем-либо, но не *во что-либо.

При этом нецеленаправленное кануть часто «по привычке» сочетается с ВИН (ср. примеры выше), а в тех случаях, когда речь идет о целенаправленном исчезновении, как кажется, предпочтителен ПР падеж (ср. рассмотренные выше примеры кануть в озерцах и болотах и кануть на долгие месяцы в водовороте крупного города, где речь идет о субъекте, умышленно скрывающемся от преследования).

Тем самым данный глагол должен пополнить список современных глаголов, содержащих в своем значении двойные семантические роли.

\section{Литература}

Апресян В. Ю. Двойные семантические роли в исходных и переносных значениях многозначных глаголов // Вопросы языкознания. 2017. № 2. С. 7-32.

АС - Активный словарь русского языка / под ред. Ю. Д. Апресяна. Вып. 1-2. М. : Языки славянской культуры, 2014 ; Вып. 3. М. ; Спб. : Нестор-История, 2017.

МАС - Малый академический словарь русского языка : в 4 т. / под ред. А. П. Евгеньевой. 4-е изд., стер. М. : Рус. яз. : Полиграфресурсы, 1999.

HКРЯ - Национальный корпус русского языка [Электронный ресурс]. URL: http://ruscorpora.ru/

Словарь XI-XIV - Словарь древнерусского языка (XI-XIV вв.) / под ред. Р.И. Аванесова и др. М. : Рус. яз., 1988-. Т. 1-.

Словарь XI-XVII - Словарь русского языка XI-XVII вв. / гл. ред. С. Г. Бархударов, Ф.П. Филин и др. М. : Наука, 1975-. Вып. 1-.

Срезневский И. И. Материалы для словаря древнерусского языка по письменным памятникам : в 3 т. СПб. : Тип. Имп. АН, 1893-1912.

СУш — Толковый словарь русского языка : в 4 т. / под ред. Д. Н. Ушакова. М. : Сов. энцикл., 1935-1940.

ЭССЯ - Этимологический словарь славянских языков. Праславянский лексический фонд / под ред. О.Н. Трубачева, А.Ф. Журавлева. М. : Наука, 1974-. Вып. 1-. 


\author{
A. V. Ptentsova \\ Lomonosov Moscow State University \\ (Russia, Moscow) \\ anna.ptentsova@gmail.com
}

\title{
RUSSIAN VERB KANUT' 'DISAPPEAR': SEMANTIC HISTORY AND THE POLYSEMY STRUCTURE
}

The article describes the history of the semantic evolution of the Russian verb kanut' ('disappear') which ascends to the *kapnoti (the semelfactive of the verb*kapati). The material of the dictionaries and of the Russian National Corpus shows that the meanings of kanut' in the East Slavic area developed in the following order: 1.1) A1 dropped on A2 'a drop of liquid A1 fell onto the surface A2'; 1.2) A1 dropped A2 on A3 'a person A1 made a drop of liquid A2 fall onto a surface A3'; 2) A1 dropped in A2 'a drop of liquid A1 fell into a liquid A2 and dissolved in it'; 3) A1 dropped in $A 2$ 'an object A1 quickly immersed in a liquid A2, usually in water, and completely ceased to be visible and accessible'; 4) $A 1$ dropped in $A 2$ 'an object $\mathrm{A} 1$, once in any place $\mathrm{A} 2$, suddenly ceased to be visible and accessible.' Noteworthy is the fact that, when used in its last (modern) meaning, kanut' appears mainly in the contexts where water (or, more rarely, another liquid) is mentioned in one way or another. Thus, the semantics of the verb remains connected with the previous meanings of the chain, which are obsolete or disappearing in modern language.

Keywords: lexical semantics, polysemy, history of the Russian language, Russian National Corpus.

\section{References}

Apresyan V.Yu. [Double semantic roles in the initial and metaphorical meanings of polysemic verbs]. Voprosy yazykoznaniya, 2017, no. 2, pp. 7-32. (In Russ.)

Apresyan Yu.D. (Ed.). Aktivnyi slovar' russkogo yazyka [The Active dictionary of the Russian language]. Moscow, St Petersburg, Yazyki slavyanskoi kul'tury Publ., NestorIstoriya Publ., 2014-2017. Vols. 1-3.

Avanesov R. I. et al. (Eds.). Slovar' drevnerusskogo yazyka (XI-XIV vv.) [The Dictionary of the Old Russian language $\left(11^{\text {th }}-14^{\text {th }}\right.$ centuries $\left.)\right]$. Moscow, Russkij Yazyk Publ., 1988-. Vols. 1-.

Barkhudarov S. G., Filin F.P. et al. (Eds.). Slovar' russkogo yazyka XI-XVII vv. [The Dictionary of the Russian language of $11^{\text {th }}-17^{\text {th }}$ centuries]. Moscow, Nauka, 1975-. Vols. 1-.

Evgen'eva A.P. (Ed.). Malyi akademicheskii slovar' russkogo yazyka [The Small academic dictionary of the Russian language]. Moscow, Russkij Yazyk Publ., 1999. Vols. 1-4.

Natsional'nyi korpus russkogo yazyka [National corpus of the Russian language]. Available at: http://ruscorpora.ru/ (accessed 02.11.2019) 
Sreznevskii I.I. Materialy dlya slovarya drevnerusskogo yazyka [Materials for the Dictionary of the Old Russian language]. St Petersburg, Imperial Acad. of Sci. Publ., 1893-1912. Vols. 1-3.

Trubachev O. N., Zhuravlev A.F. (Eds.). Etimologicheskii slovar' slavyanskikh yazykov. Praslavyanskii leksicheskii fond [The Etymological dictionary of Slavic Languages. Protoslavic lexical fund]. Moscow, Nauka Publ., 1983-. Vols. 1-.

Ushakov D.N. (Ed.). Tolkovyi slovar' russkogo yazyka [The explanatory dictionary of the Russian language]. Moscow, Sovetskaya Entsiklopediya Publ., 1935-1940. Vols. 1-4. 